physicians more aware of the risks which are taken if this practice is followed.

In addition, there is a requirement for the liquid oral preparations for geriatric and psychiatric use and for patients unable to swallow solid dosage formulations.

Many other pharmaceutical preparations are available which, if used incorrectly, can lead to adverse effects although their clinica worth is not questioned. We do not feel that tetracycline should be an exception to this rule.

P G Brock Medical Adviser MaRyanne RoaCH Medical Information Manager,
Lederle Laboratories

Gosport, Hants

\section{Treatment of spasmodic torticollis} with diazepam

SIR,-With reference to your excellent leading article on spasmodic torticollis (16 September, p 786) we wish to emphasise the efficacy of diazepam in the management of this disorder.

Case 1-In December 1976 a 19-year-old whit woman presented in the emergency departmen with the typical picture of spasmodic torticollis. Intravenous diazepam $10 \mathrm{mg}$ was given with immediate and full remission of this condition in $7 \mathrm{~min}$.

Case 2-In December 1977 a 19-year-old white man was brought to the emergency department with fairly diagnostic features of spasmodic torticollis. Based on previous experience diazepam $5 \mathrm{mg}$ was given intravenously with immediate and dramatic recovery. Relapse has not occurred in either of the patients to date.

Spasmodic torticollis is an uncommon problem generally of unknown aetiology. A strong psychosomatic component has been suggested. There is no specific therapy except when an underlying correctable process is found. Diazepam has been used successfully in the management of this disorder previously and these cases further emphasise its efficacy. Hence we respectfully submit that diazepam should be considered in the management of spasmodic torticollis before the patient is referred to psychiatric or neurosurgical departments.

SAEEd Ahmad

Department of Medicine,

Fairmont General Hospital

M K MEeran

\author{
Department of Medicine, \\ LSU Medical Center, \\ ${ }^{1}$ Bianchine, J R, and Bianchine, J W, Southern \\ Medical fournal, 1971, 64, 893.
}

\section{BPAS and AID}

SIR,-I regret that the information given by Diane Munday (16 December, p 1712) does not "clear up ... the anxieties . . . in people's minds" about BPAS's new service but only increases them, since it is clear that they still do not understand the ethical and practical problems involved. ${ }^{1}$ For example, if, as she says, the husband's semen was used in two out of three cases then this was not AID (donor insemination) but AIH (husband insemination), where there are few religious or ethical objections. In that case either BPAS does not distinguish between AIH and AID or, if it does, then AID was being considered where it was not required, thus confirming my argument that AID should only be performed by experts in male and female infertility.

She states that "BPAS is not going to exclude anybody for AI by laying down prejudged criteria." Why not? There is no parallel in her comparison of sterilisation requirements; after sterilisation there should be no end-product of a child, "whose welfare should be paramount," whereas after AID there is. That child will be born into a singleparent family. I still maintain that a oneparent family should not be accepted for AID with the very high risk that both child and mother will be a burden to themselves and to society. ${ }^{2}$

\section{Manchester \\ Sandler, B, Guardian, 8 February 1958. \\ ' Davis, J A, Lancet, 1978, 2, 1257.}

BERNARD SANDLER

\section{DIY blood-pressure machines}

SIR,-It is well recognised that elevated blood pressure is associated with increased risk of cerebrovascular and also possibly of cardiovascular disease and death. We also know that high blood pressure is usually without symptoms. It is therefore sensible to suggest that all adults should occasionally have their blood pressure measured. A possible way to do this is to educate family doctors to ensure that all their patients have this done. Inevitably such an approach would take a lot of time and effort and it would be much simpler for the public to take their own blood pressure, as they do their own weight.

We therefore find it remarkable that a BMA spokesman should appear on television and suggest that "do it yourself" blood-pressure machines may do more harm than good, and that people need only have their blood pressure taken by their general practitioner if they have symptoms such as headache, dizziness, etc.

J R D BROWN L THOMAS HARRINGTON C M LOCKWOOD A C HaLl

Lichfield, Staffs

\section{Influence of diphenylhydantoin on the} effect of streptozotocin

SIR,-Dr A B Atkinson and his colleagues report on an apud cell carcinoma in a diabetic patient treated with streptozotocin (18 November, p 1397). We observed a 24 -year-old male patient suffering from an organic hypoglycaemic syndrome caused by a metastatic apud cell carcinoma of the pancreas. The polypeptide hormone contents of $1 \mathrm{~g}$ of wet tumour tissue were: insulin, 34.66 IU (proinsulin, $37 \%$ ); gastrin, $211 \mathrm{pg}$; glucagon, 4.725 : $\mathrm{g}$ (proglucagon, molecular weight 9000 , $\left.46^{\circ}{ }^{\circ}\right)$. The patient was treated with streptozotocin and diphenylhydantoin as adjunctive therapy since we had not experienced any appreciable effect with diazoxide, ${ }^{1} 2 \mathrm{~g}$ of streptozotocin being given every 4 days together with $400 \mathrm{mg}$ of diphenylhydantoin daily. After the third dose of streptozotocin nausea and vomiting forced us to stop oral treatment with diphenylhydantoin. Five days later the patient again received $2 \mathrm{~g}$ of streptozotocin but without diphenylhydantoin. As shown in the figure, when diphenylhydantoin

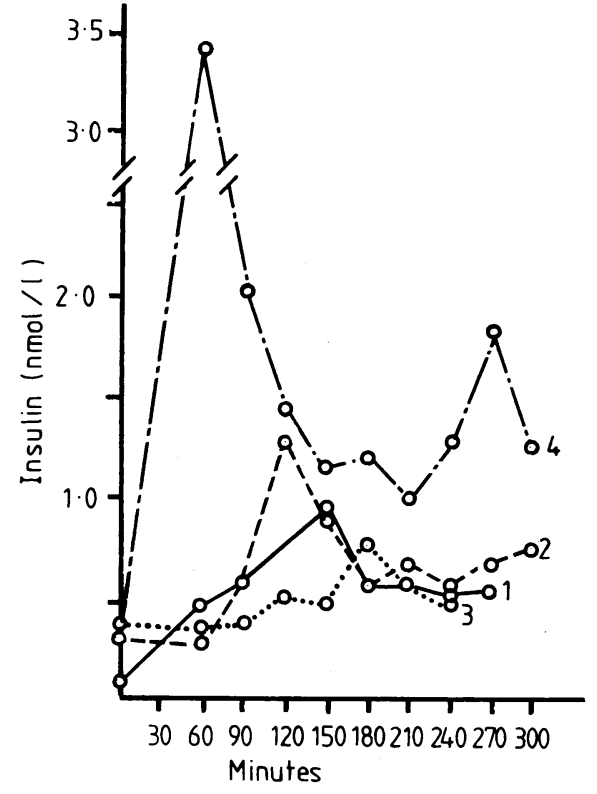

Responses of plasma insulin to $2 \mathrm{~g}$ of streptozotocin intravenously during (curves 1,2 , and 3 ) and after (curve 4) diphenylhydantoin treatment.

Conversion: SI to traditional units-Insulin: $1 \mathrm{nmol} / 1 \approx 145 \mathrm{mU} / \mathrm{l}$.

was administered simultaneously streptozotocin caused only slight insulin release compared with the effect observed after the withdrawal of diphenylhydantoin, when streptozotocin caused a marked insulin response. Thus pretreatment with diphenylhydantoin seems to protect the beta cells from the cytotoxicity of streptozotocin as it does in the case of alloxan, ${ }^{2}$ and the characteristic insulin release induced by streptozotocin fails to occur. We suggest that when streptozotocin is given simultaneous treatment with diphenylhydantoin should be avoided.

L KORANYI

L GERO

1st Department of Medicine

Semmelweis University, Budapest, Hungary ' Knopp, $\mathrm{R} \mathrm{H}$, et al, Archives of Internal Medicine,
$1972,130,903$.
${ }^{2}$ Schimmel, $\mathrm{R}$, and Graham, D, Hormone and Metabolic Research, 1974, 6, 465 .

\section{The troubles at Normansfield}

SIR,-During the early troubles at Normansfield Hospital I was president of the Consultants' Association, to which Dr Terry Lawlor subscribed. One point might be of interest to your readers; to the best of my knowledge it did not emerge from the official inquiry.

On the collapse of the ad hoc inquiry chaired by Mr G Kidner, strenuous efforts were made to reach a settlement in a highly confidential manner. We were all aware that neither Dr Lawlor nor any other party was likely to come out of a Section 70 inquiry unscathed, though the degree of trauma suffered by almost all parties has surprised some of us.

A compromise was indeed reached with the overt or covert agreement of all parties concerned. I have no intention of revealing the terms save to disclose that under its terms Dr Lawlor was to be offered another, similar consultant post in the same region. The terms of the compromise were put to Dr Lawlor in chambers in my presence; I advised him most strongly to accept them. That he refused them 